\title{
Photoredox Catalysis for Polymerization Reactions
}

\author{
Jacques Lalevée ${ }^{\star a}$, Mohamad-Ali Tehfe ${ }^{a}$, Fabrice Morlet-Savarya ${ }^{a}$ Bernadette Graffa, \\ Frédéric Dumur $^{\mathrm{b}}$, Didier Gigmes ${ }^{\mathrm{b}}$, Nicolas Blanchard ${ }^{\mathrm{c}}$, and Jean-Pierre Fouassier ${ }^{\mathrm{d}}$
}

\begin{abstract}
Photoredox catalysis is now well-known in organic synthesis for the formation of free radicals under very soft irradiations conditions (e.g. sunlight, household fluorescence or LED bulbs, Xe lamp). This method has been introduced here to the polymer chemistry area to initiate ring opening polymerizations (ROP) or free radical polymerizations (FRP). The present paper will give an up-to date situation of the photocatalyst achievements in FRP and ROP.
\end{abstract}

Keywords: Free radical · Free radical polymerization · Photoinitiators · Photoredox catalysis · Ring opening polymerization

\section{Introduction}

Photoredox catalysis under very soft irradiation conditions (e.g. sunlight, household fluorescence or LED bulbs, Xe lamp) is now well-known in organic synthesis. ${ }^{[1-5}$ and refs herein] In very recent years, this method has also been introduced for the synthesis of polymers (see a review in ref. [6]) i.e. to initiate a ring opening polymerization (ROP) or a free radical photopolymerization (FRP). In this area, the photopolymerization reaction is initiated using photoinitiators (PI, commonly organic PI) that generate reactive species (radicals, cations, anions, radical cations, acids, bases) and are consumed during the light exposure. ${ }^{[7]}$ The use of organometallic compounds as PIs has also been reported many years ago (see a review in ref. [8]) and reintroduced in some recent papers dealing with e.g. $\mathrm{Cr}$, Ti, Fe, Rh, W, Ru, Ir-based derivatives. On this occasion, it appears that a photoredox catalysis approach can be realized thereby

\footnotetext{
${ }^{\text {*Correspondence: Prof. J. Lalevée }}{ }^{a}$ E-mail address: *j.lalevee@uha.fr

alnstitut de Science des Matériaux de Mulhouse IS2M - LRC CNRS 7228 - ENSCMu-UHA 15, rue Jean Starcky, 68057 Mulhouse Cedex, France bInstitut de Chimie Radicalaire UMR CNRS 7273 Equipe CROPS, Aix-Marseille Université Avenue Escadrille Normandie-Niemen, Case 542, 13397 Marseille Cedex 20, France

cUniversity of Haute Alsace, ENSCMu

Laboratory of Organic and Bioorganic Chemistry

3 rue Alfred Werner, 68093 Mulhouse Cedex, France

dUniversity of Haute Alsace, ENSCMu
}

3 rue Alfred Werner, 68093 Mulhouse Cedex, France providing a suitable selection of the photoinitiating system. ${ }^{\left[{ }^{9-11]}\right.}$ Metal and metalfree PICs are currently proposed.

This new approach allows the development of novel photoinitiating systems (where the photoinitiator is referred now as photoinitiator catalyst (PIC)) that bring new properties such as i) almost no initiator consumption, ii) photosensitivity to UV, visible lights, green or red laser lines, iii) operation under much lower light intensities (household lamps and LED bulbs, sunlight), iv) easy production of radical or ionic initiating species for the FRP of acrylates or the ring opening polymerization (ROP) of epoxides, respectively, v) possible dual behavior (simultaneous generation of radicals and ions that ensure the formation of $e . g$. an epoxy/acrylate interpenetrated network IPN). The present paper will briefly summarize the up-to date situation of the PIC achievements in FRP and ROP.

\section{Photoinitiator Catalysts Working through an Oxidation Cycle for ROP}

\subsection{Chemical Mechanisms}

Through light excitation in the presence of an electron acceptor (eA), the oxidized form $\left(\mathrm{PIC}^{\circ+}\right)$ of the photoinitiator catalyst PIC is produced (reaction (1)). An electron donor compound (eD) should be added to recover the PIC in its initial ground state (reaction (2)). The choice of suitable eA compounds being rather complicated, a cleavable positively charged electron donor A-B ${ }^{+}$instead of eA might be used (reaction (3)). The ease of the radical $\rightarrow$ cation step (reaction (4)) as well as the nature of the cationic center remains associated with the nature of $\mathrm{A}-\mathrm{B}^{+}$. For example, us- ing a $\mathrm{Ru}$ complex (e.g. Ru(bipyridine $)_{3}{ }^{2+}$ ) as PIC, a diphenyl iodonium salt $\mathrm{Ph}_{2} \mathrm{I}^{+}$as $\mathrm{A}^{-} \mathrm{B}^{+}$, a phenyl radical $\mathrm{Ph}^{\cdot}$ is formed but the oxidation reaction of $\mathrm{Ph}^{*}$ by $\mathrm{PIC}^{*+}$ is clearly difficult. ${ }^{[9,10]}$ An improvement of the situation is obtained by introducing $\mathrm{A}-\mathrm{B}^{+}$and a hydrogen donor $\mathrm{DH}$ into the system. The

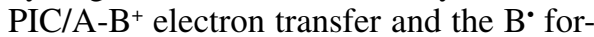
mation occur as depicted in reaction (3). Then, the $\mathrm{B} / \mathrm{DH}$ hydrogen abstraction leads to a new D' radical (reaction (5)) that can be more easily oxidized by $\mathrm{PIC}^{\circ+}$ (reaction (6)).

$$
\begin{aligned}
& \mathrm{PIC}+\mathrm{eA} \rightarrow \mathrm{PIC}^{\bullet+}+\mathrm{eA}^{\bullet} \text { (light) } \\
& \mathrm{PIC}^{\bullet+}+\mathrm{eD} \rightarrow \mathrm{PIC}+\mathrm{eD}^{\bullet+} \\
& \mathrm{PIC}+\mathrm{A}-\mathrm{B}^{+} \rightarrow \mathrm{PIC}^{+\bullet}+{\mathrm{A}-\mathrm{B}^{\bullet}}^{\bullet} \\
& (\text { light }) \text { and } \mathrm{A}-\mathrm{B}^{\bullet} \rightarrow \mathrm{A}+\mathrm{B}^{\bullet} \\
& \mathrm{B}^{\bullet}+\mathrm{PIC}^{+} \rightarrow \mathrm{PIC}+\mathrm{B}^{+} \\
& \mathrm{B}^{\bullet}+\mathrm{DH} \rightarrow \mathrm{D}^{\bullet}+\mathrm{BH} \\
& \mathrm{D}^{\bullet}+\mathrm{PIC}^{\bullet+} \rightarrow \mathrm{D}^{+}+\mathrm{PIC}
\end{aligned}
$$

\subsection{Examples of Polymerization Initiating Systems}

Typical monomer conversion vs. time profiles for the visible light-induced ring opening polymerization (ROP) of an epoxide in the presence of the newly developed PIC based systems are displayed in Fig. 1 and 2.

Based on reactions (3), (5) and (6), examples of metal-containing photoinitiator catalysts for ROP are found with $\mathrm{Ru}$ or $\mathrm{Ir}$ complexes (e.g. Ru(bipyridine $)_{3}{ }^{2+}, \quad \mathrm{Ru}(\text { phenanthroline })_{3}{ }^{2+}$, $\mathrm{Ir}$ (phenylpyridine) $)_{3}$ ) as $\mathrm{PIC}, \mathrm{Ph}_{2} \mathrm{I}^{+}$as $\mathrm{A}-\mathrm{B}^{+}$ and a silane $\mathrm{R}_{3} \mathrm{SiH}$ (e.g. tris(trimethylsilyl) silane: (TMS) ${ }_{3} \mathrm{Si}-\mathrm{H}$ ) as DH. Silyl radicals $\mathrm{R}_{3} \mathrm{Si}^{\cdot}$ and silylium cations $\mathrm{R}_{3} \mathrm{Si}^{+}$are formed in reactions (5) and (6) respectively; an ad- 

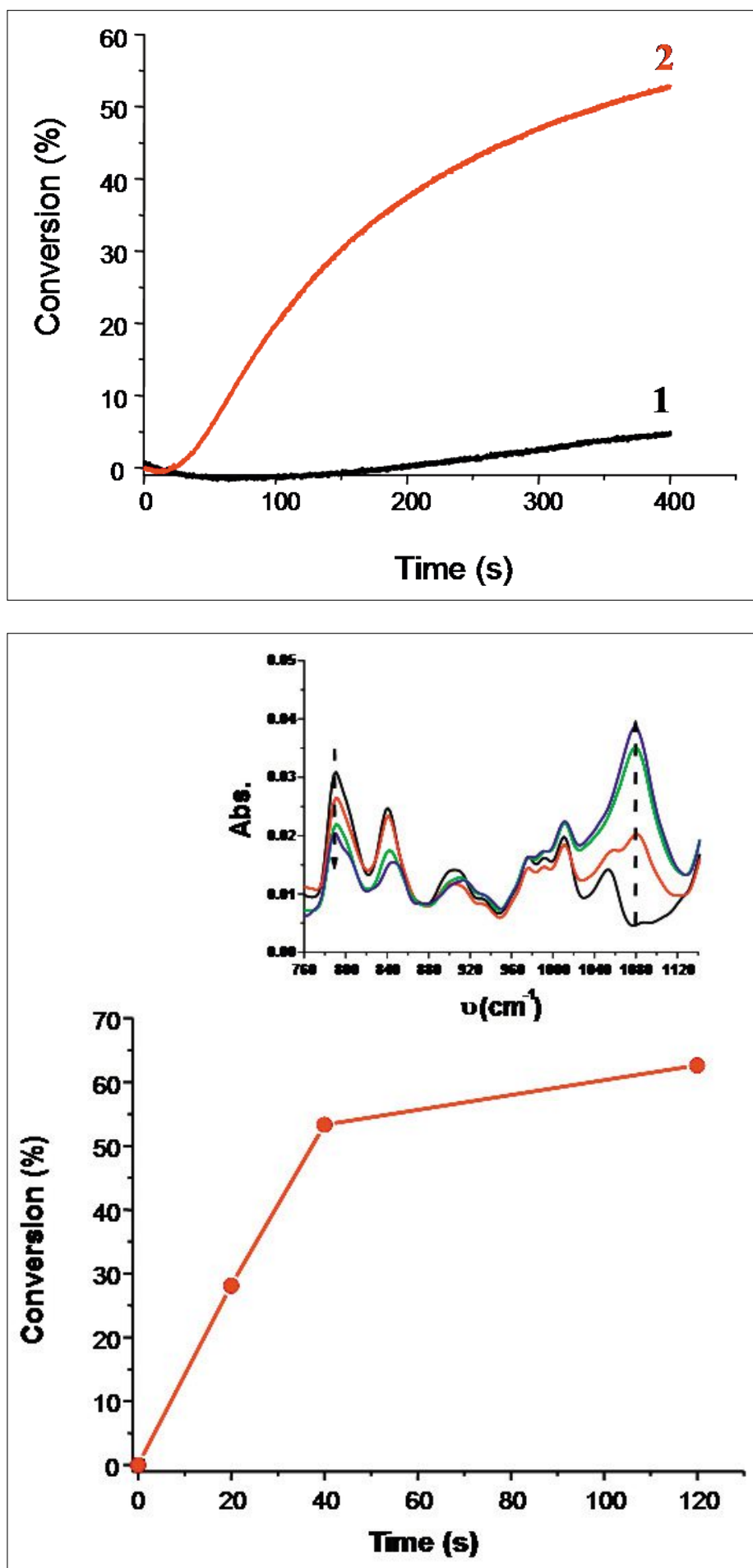

Fig. 2. Polymerization profiles of (3,4-epoxycyclohexane)methyl 3,4-epoxycyclohexylcarboxylate (EPOX) (conversion vs. time) under sunlight in the presence of 5,12 bis (phenylethynyl) naphthacene/ (TMS) ${ }_{3} \mathrm{Si}-\mathrm{H} / \mathrm{Ph}_{2} \mathrm{I}^{+}$ $(0.5 \% / 3 \% / 2 \% \mathrm{w} / \mathrm{w})$. Insert: IR spectra taken at different irradiation times $(0$ to 120 s) (In Mulhouse, November 2011).

ditional reaction (6') increases the yields in both phenyl radicals and silyliums. ${ }^{[9,10]}$ In Fig. 1, the presence of the $\mathrm{R}_{3} \mathrm{SiH}$ is decisive to obtain a good to excellent polymerization profile (curve 2 vs. curve 1) in agreement with the excellent polymerization initiating ability of the silyliums (reaction (6)).

$\mathrm{D}^{\bullet}+\mathrm{Ph}_{2} \mathrm{I}^{+} \rightarrow \mathrm{D}^{+}+\mathrm{Ph}_{2} \mathrm{I}^{\bullet} \rightarrow \mathrm{D}^{+}+\mathrm{Ph}^{\bullet}+\mathrm{PhI}$

$\mathrm{PIC}+\mathrm{eD} \rightarrow \mathrm{PIC}^{\bullet-}+\mathrm{eD}^{\bullet}$ (light)

$\mathrm{PIC}^{--}+\mathrm{E}-\mathrm{F} \rightarrow \mathrm{PIC}+\mathrm{E}_{-} \mathrm{F}^{\cdot-} \rightarrow \mathrm{PIC}+\mathrm{E}^{\cdot}+\mathrm{F}^{-}$

$\mathrm{PIC}^{\bullet-}+\mathrm{G}^{-\mathrm{H}^{+}} \rightarrow \mathrm{PIC}+\mathrm{G}^{-} \mathrm{H}^{\bullet} \rightarrow \mathrm{PIC}+\mathrm{G}+\mathrm{H}^{\bullet}$ ed: they involve an anthracene derivative (bis[(triisopropylsilyl)ethynyl]anthracene $)^{[10 \mathrm{~b}]}$ as $\mathrm{PIC}, \mathrm{Ph}_{2} \mathrm{I}^{+}$as $\mathrm{A}^{-\mathrm{B}^{+}}$and (TMS) $)_{3} \mathrm{Si}-\mathrm{H}$ as DH. Using other polycyclic aromatic hydrocarbons (PAHs) (e.g. pyrene, naphthacene, pentacene) as $\mathrm{PIC}, \mathrm{Ph}_{2} \mathrm{I}^{+}$ as ${\mathrm{A}-\mathrm{B}^{+}}$and (TMS) $)_{3} \mathrm{Si}-\mathrm{H}$ as $\mathrm{DH}$ allows highly efficient ROP processes. ${ }^{[13]} \mathrm{A}$ tunable absorption of the system is achieved by a proper selection of the PAHs (from UV to the red light). This is presumably the most famous example for an epoxy ROP under a green $(514 \mathrm{~nm})$, yellow $(591 \mathrm{~nm})$ and red $(630 \mathrm{~nm})$ LED bulb exposure.

Using 5,12-bis(phenylethynyl)naphthacene as PIC (Fig. 2), the oxidative cycle with (TMS) ${ }_{3} \mathrm{Si}-\mathrm{H}$ and $\mathrm{Ph}_{2} \mathrm{I}^{+}$leads to silyliums which can easily initiate an epoxy ROP. ${ }^{[13]}$ Remarkably, this polymerization reaction is very fast under sunlight.

\section{Photoinitiator Catalysts Working through a Reduction Cycle}

\subsection{Chemical Mechanisms}

In this catalytic reductive cycle, the PIC is reduced through a photoinduced electron transfer with an electron donor eD (reaction (7)). A suitable E-F (or G- $\mathrm{H}^{+}$) compound leads to a regeneration of PIC and the creation of a radical and an ion (reaction (8)) or a radical and a neutral product (reaction (9)).

\subsection{Examples of Polymerization Initiating Systems}

Fig. 3 and 4 show typical monomer conversion vs. time profiles for the visible light-induced polymerization of an acrylate (upon low light intensity exposure and under air) in the presence of the new PIC based systems.

The first mentioned initiating systems based on this photoredox catalysis approach for the photopolymerization of acylates were composed of a Ru complex ( $\mathrm{Ru}$ (bipyridine) ${ }_{3}{ }^{2+}$ ) as PIC, an amine (methyldiethanolamine) as $\mathrm{eD}$ and an alkyl halide (phenacyl bromide) as E-F. ${ }^{[9 a}$ In this mechanism, a reduced form of the $\mathrm{Ru}$ complex is formed (PIC*- $=$ $\mathrm{Ru}$ (bipyridine $)_{3}^{+}$) and a phenacyl radical $\left(\mathrm{E}^{*}\right)$ is produced upon the subsequent cleavage of the phenacyl halide radical anion $\left(\mathrm{E}-\mathrm{F}^{\circ}\right)$. Later on, other amines and alkyl halides were proposed. ${ }^{[11]}$

Iridium complexes (Fig. 5) can also be used as PICs in this reductive cycle. In combination with an amine and an alkyl halide, Ir complexes can very efficiently initiate the free radical polymerization of acrylates (Fig. 3). The presence of the Ir complexes as PICs is decisive for the initiating ability of these systems (Fig. 3, curve 1 vs. curves 2-4).

Photopolymerization reactions us- 

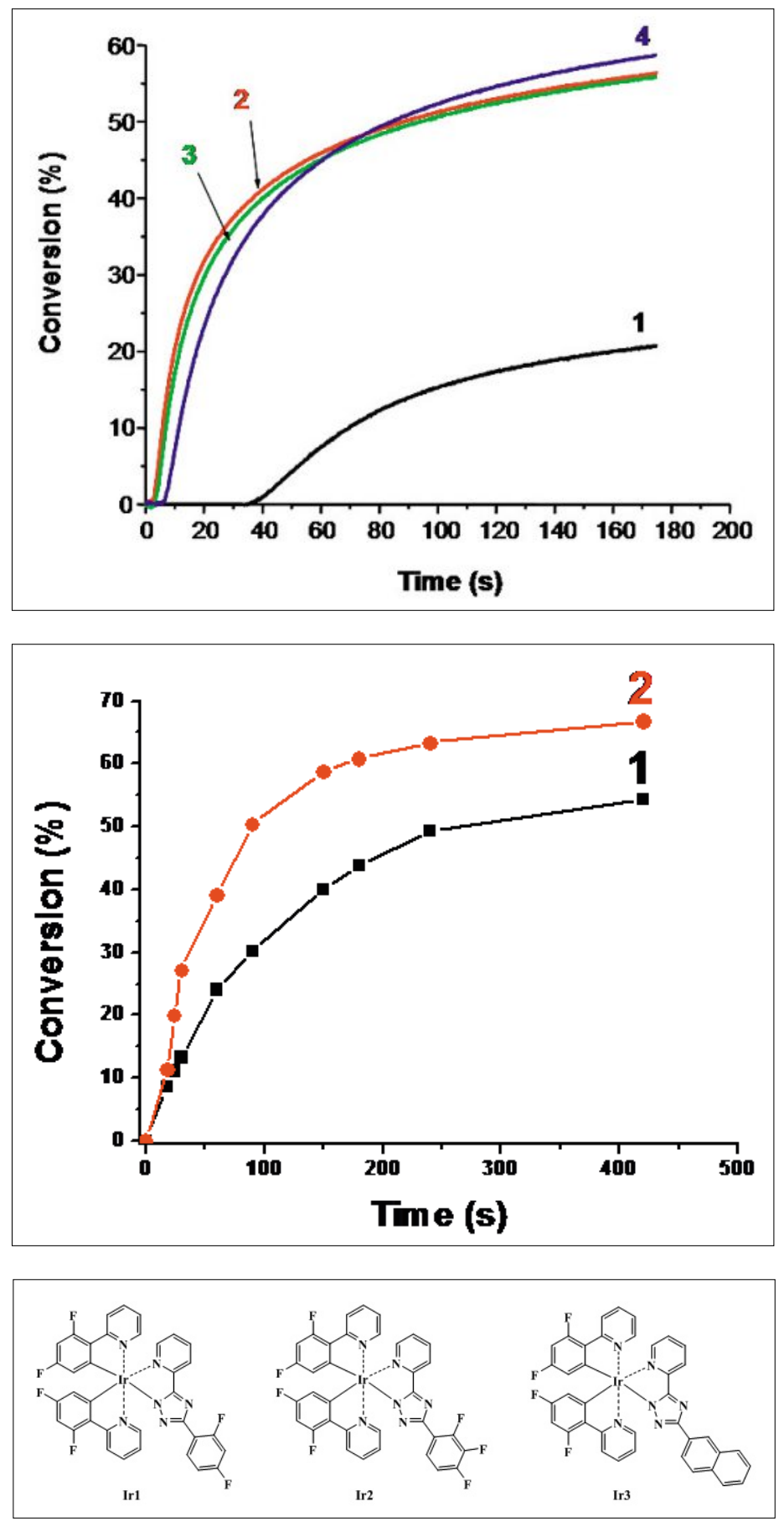

ing metal-free PICs can also be operating through such a reduction cycle. They involve polycyclic aromatic hydrocarbons (e.g. pyrene, anthracene, naphthacene, pentacene) as PIC, an amine (ethyldimethylaminobenzoate or methyldiethanolamine) as eD and an halide (phenacyl bromide) as E-F.[10b] The system is sensitive to lights actually ranging from 300 to 700 $\mathrm{nm}, e . g$. in combination with an amine and an alkyl halide, 5,12-bis(phenylethynyl) naphthacene can be used in a reductive cycle to initiate a FRP process of trimethylol propane triacrylate TMPTA (Fig. 4). Other PICs might be dyes but preliminary experiments suggest that their behavior as PICs is not straightforward.

Another example concerns the use of a $\mathrm{Ru}$ complex as PIC, a violanthrone
Fig. 3. Polymerization profiles of pentaerythritol tetraacrylate (EPT) upon a Xenon lamp irradiation $(\lambda>390 \mathrm{~nm})$ in laminate in the presence of (1) N-methyldiethanolamine (MDEA)/phenacylbromide (PABr) $(4.5 \% / 3 \% \mathrm{w} / \mathrm{w})$; (2) $\mathrm{Ir} 1 / \mathrm{MDEA} / \mathrm{PABr}$ (0.2\%/4.5\%/3\% w/w); Ir2/MDEA/ $\mathrm{PABr}(0.2 \% / 4.5 \% / 3 \%$ w/w), Ir3/MDEA/ $\operatorname{PABr}(0.2 \% / 4.5 \% / 3 \%$ $w / w)$.

Fig. 4. Polymerization profiles of trimethylol propane triacrylate (TMPTA) upon a XeHg lamp irradiation $(\lambda$ $>390 \mathrm{~nm}$ ) in laminate in the presence of (1) 5,12-bis (phenylethynyl)naphthacene/ ethyldimethylaminobenzoate (EDB)/diethyl-2bromomalonate $(0.5 \% / 4.5 \% / 3 \% \mathrm{w} / \mathrm{w})$; (2) 5,12-bis (phenylethynyl)naphthacene/ ethyldimethylaminobenzoate (EDB)/phenacyl bromide (PABr) $(0.5 \% / 4.5 \% / 3 \% \mathrm{w} / \mathrm{w})$.

Fig. 5.

derivative as $\mathrm{eD}, \mathrm{Ph}_{2} \mathrm{I}^{+}$salt as $\mathrm{G}-\mathrm{H}^{+}$and (TMS) ${ }_{3} \mathrm{Si}-\mathrm{H}$. A phenyl radical is produced from $\mathrm{G}-\mathrm{H}^{*}\left(=\mathrm{Ph}_{2} \mathrm{I}^{\circ}\right)$. As in reactions (5), (6) and $\left(6^{\prime}\right)$, the silane ensures the formation of $\mathrm{R}_{3} \mathrm{Si}^{\circ}$ and $\mathrm{R}_{3} \mathrm{Si}^{+}$. ${ }^{[13,14]}$ This has led to an efficient ROP process under a green laser line at $532 \mathrm{~nm}$.

\section{Conclusion}

As a conclusion, photoinitiator catalysts PICs appear as a new class of photoinitiating systems usable in FRP and ROP which should bring a novel potential in photopolymerization reactions under very soft irradiation conditions. New PIC, eA, eD, A-B ${ }^{+}$, D-H, E-F, G-H ${ }^{+}$can likely be designed and new routes might also be proposed.
Received: February 8, 2012

[1] a) D. A. Nicewicz, D. W. C. MacMillan, Science 2008, 322, 77; b) D. A. Nagib, M. E. Scott, D. W. C. MacMillan, J. Am. Chem. Soc. 2009, 131 10875; c) H.-W. Shih, M. N. Van der Wal, R. L. Grange, D. W. C. MacMillan, J. Am. Chem. Soc. 2010, 132, 13600

[2] a) J. M. R. Narayanam, C. R. J. Stephenson, Chem. Soc. Rev. 2011, 40, 102; b) C. Dai, J. M. R. Narayanam, C. R. J. Stephenson, Nature Chem. 2011, 3, 140 .

[3] a) M. A. Ischay, Z. Lu, T. P. Yoon, J. Am. Chem. Soc. 2010, 132, 8572; b) T. P. Yoon, M. A. Ischay, J. Du, Nature Chem. 2010, 2, 527.

[4] a) M. H. Larraufie, R. Pellet, L. Fensterbank, J. P. Goddard, E. Lacôte, M. Malacria, C. Ollivier, Angew. Chem. Int. Ed. 2011, 50, 4463; b) T. Courant, G. Masson, Chem. Eur. J. 2011, DOI: 10.1002/chem.201103062.

[5] a) M. Neumann, S. Fuldner, B. Konig, K. Zeitler, Angew. Chem. Int. Ed. 2011, 50, 951; b) K. Zeitler, Angew. Chem. Int. Ed. 2009, 48, 9785 .

[6] J. P. Fouassier, J. Lalevée, 'Photoinitiators for Polymer Synthesis: Scope, Reactivity and Efficiency', Wiley-VCH., Weinheim, to be publ. 2012.

[7] a) J. P. Fouassier, 'Photoinitiation, Photopolymerization, Photocuring', Hanser, Münich, 1995; b) S. Davidson, 'Exploring the Science, Technology and Application of UV and EB Curing,, Sita Technology Ltd, London, 1999; c) D. C. Neckers, 'UV and EB at the Millenium', Sita Technology, London, 1999; d) K. A. Dietliker, 'Compilation of Photoinitiators Commercially Available for UV Today', Sita Technology Ltd, London, 2002; e) 'Photoinitiated Polymerization', Eds. K. D. Belfied, J. V. Crivello, ACS Symposium series 847, Washington DC, 2003; f) 'Basics of Photopolymerization Reactions', Eds. J. P. Fouassier, X. Alloas, Research Signpost, Trivandrum India, 2010.

[8] A. F. Cunningham Jr, V. Desobry, in 'Radiation Curing in Polymer Science and Technology', Eds. J. P. Fouassier, J. F. Rabek, Elsevier Science Publishers LTD, London, 1993, vol. 2, pp 323-374.

[9] a) J. Lalevée, N. Blanchard, M. A. Tehfe, F. Morlet-Savary, J. P. Fouassier, Macromol. 2010, 43, 10191; b) J. Lalevée, N. Blanchard, M. A. Tehfe, M. Peter, F. Morlet-Savary, J. P. Fouassier, Macromol. Rapid Comm. 2011, 32, 917; c) J. Lalevée, N. Blanchard, M. A. Tehfe, M. Peter, F. Morlet-Savary, D. Gigmes, J. P. Fouassier, Polym. Chem. 2011, 2, 1986; d) J. Lalevée, N. Blanchard, M. A. Tehfe, M. Peter, F. Morlet-Savary, J. P. Fouassier, Polym. Bull., 2012, 68, 341

[10] a) J. Lalevée, M. Peter, F. Dumur, D. Gigmes, N. Blanchard, M. A. Tehfe, F. Morlet-Savary, J. P. Fouassier, Chem. Eur. J. 2011, 17, 15027; b) M. A. Tehfe, J. Lalevée, F. Morlet-Savary, B. Graff, N. Blanchard, J. P. Fouassier, ACS Macro Lett. 2012, 1, 198

[11] G. Zhang, I. Y. Song, K. H. Ahn, T. Park, W. Choi, Macromol. 2011, 44, 7594.

[12] a) M.-A. Tehfe, J. Lalevée, D. Gigmes, J. P. Fouassier, Macromol. 2010, 43, 1364; b) M.-A Tehfe, J. Lalevée, D. Gigmes, J. P. Fouassier, J. Polym. Sci., Part A: Polym. Chem. 2010, 48 , 1830.

[13] M. A. Tehfe, J. Lalevée, F. Morlet-Savary, B Graff, N. Blanchard, J. P. Fouassier, Macromol. 2012, 45, 1746.

[14] a) M.-A. Tehfe, D. Gigmes, F. Dumur, D Bertin, F. Morlet-Savary, B. Graff, J. Lalevée, J.-P. Fouassier, Polym. Chem. 2012, Advance Article, DOI: $10.1039 /$ C1PY00460C; b) M.-A. Tehfe, J. Lalevée, F. Morlet-Savary, B. Graff, J. P. Fouassier, Macromol. 2011, 44, 8374. 